Working Paper 06-29 (11)

Statistics and Econometrics Series 06

May 2006
Departamento de Estadística

Universidad Carlos III de Madrid

Calle Madrid, 126

28903 Getafe (Spain)

Fax (34) 91 624-98-49

\title{
MODELLING MONETARY TRANSMISSION IN UK MANUFACTURING INDUSTRY $^{1}$
}

\author{
Juan de Dios Tena and A. R. Tremayne ${ }^{2}$
}

\begin{abstract}
This paper studies the transmission of monetary policy to industrial output in the UK. In order to capture asymmetries, a system of threshold equations is considered. However, unlike previous research, endogenous threshold parameters are allowed to be different for each equation. This approach is consistent with economic intuition and is shown to be of tangible importance after suitable econometric evaluation. Results show evidence of cross-sectional differences across industries and asymmetries in some sectors. These findings contribute to the debate about the importance of alternative economic theories to explain these asymmetries and support the use of a sectorally disaggregated approach to the analysis of monetary transmission.
\end{abstract}

Keywords: vector autoregression, threshold models, impulse-response functions, sectoral disaggregation.

JEL Codes: C3, E3, L1.

${ }^{1}$ We appreciate the comments by Terry Mills, Alex Cukierman, Zvi Hercowitz, Michel Strawchinsky and participants at seminars at The University of Newcastle upon Tyne, Tel-Aviv University, Bank of Israel, Central Bank of Chile, Universidad Católica de Chile and The Royal Economic Society Annual Conference 2006. We gratefully acknowledge the use of the Gauss programs provided by Bruce Hansen in his webpage (http://www.ssc.wisc.edu/ bhansen). Any remaining errors are the authors' responsibility.

${ }^{2}$ Corresponding author: Juan de Dios Tena, Universidad de Concepcion, Departamento de Economia, Victoria 471 - Oficina 242 - Concepcion, Chile, email: juande@udec.cl and Universidad Carlos III, Departamento de Estadística, C/Madrid 126. 28903 Getafe (Madrid), Spain, e-mail: jtena@est-econ.uc3m.es; A, R, Tremayne, University of York and University of Sydney 


\section{Introduction}

The use of the vector autoregressive (VAR) approach advocated by Sims (1980) has become a familiar tool in the field of monetary policy; see Christiano et al. (1999) for a discussion on VAR identification for the linear case and, inter alia, Sims (1992) and Bernanke and Blinder (1992) for relevant examples. An important feature of this methodology is that all relevant economic variables in the system are endogenous. However, a limitation of traditional VAR models lies in the fact that they are built on the assumption of linearity. In this setting, this means between monetary policy and other fundamentals. This is a drawback as economic theory suggests the possibility of asymmetries in the monetary transmission mechanism.

Attention might be drawn to three different strands of literature in this context. The first of these refers to the presence of 'frictions' in credit markets. The leading contributions in this field have been made by authors such as Greenwald and Stiglitz (1993), Bernanke and Blinder (1992) and Kiyotaki and Moore (1997). According to this theory, asymmetric information in the credit market leads to a difference between the cost of internal and external finance that depends on the financial position of the borrowers. Thus, the effect of monetary shocks depends largely on the business cycle, as financial restrictions are more likely in recession periods. Bernanke et al. (1996) suggest that, in periods of financial restrictions, monetary shocks can have a long lasting effect on real activity. They call this phenomenon the financial accelerator.

Others, including Ball and Mankiw (1994), consider a theoretical model based on the assumption of a convex short-run aggregate supply curve. Convexity implies that the slope of this curve is steeper at higher levels of output and inflation. Asymmetries arise because a shift in aggregate demand induced by a monetary shock will have a stronger effect on output and a weaker effect on inflation when the economy is in recession, with the converse holding when the economy is in expansion.

The third strand of literature highlights the importance of uncertainty and its effects on investment and production decisions. Abel and Eberly (1999) present a model where firms only invest if the expected marginal value product exceeds the user cost of capital which, under irreversibility, depends positively on uncertainty about future demand. They show that, under general conditions, economic uncertainty weakens the response of investment to demand shifts.

This paper presents a methodology for estimating asymmetries in the transmission of monetary shocks to industrial output using a system of simultaneous threshold equations for the UK. We choose threshold models because they are an obvious way to capture asymmetries in the transmission of monetary shocks. Moreover, they can be considered a simplification of other, more sophisticated, nonlinear models. Our work is in similar vein to the recent papers by Balke (2000) and Atanasova (2003). They propose threshold vector autoregressive (TVAR) models requiring that the same threshold governs all the equations in the system. They study monetary transmission and find evidence of asymme- 
tries depending on the state of the business cycle for the US and UK respectively.

In this paper, the assumption of a common threshold is relaxed, allowing the different equations to have different threshold parameters. There are sound economic reasons for proceeding in this way. For example, Cukierman and Muscatelli (2003) and Dolado et al. (2000) find evidence of nonlinearities in the Taylor rule and suggest that this might be due to the presence of asymmetric preferences with respect to output and inflation by policy makers. Further, Schaling (1999) and Dolado et al. (2005) consider the case where the equation that relates inflation to output and other fundamentals, the so-called Phillips curve, is nonlinear, but convex, and study how this can generate nonlinearities in the interest rate equation. In this context, given that economic theory suggests that different structural equations may have different types of nonlinearities, it is natural to specify and estimate a structural system that allows each equation to have its own threshold. More specifically, we consider a VAR system in which estimated parameters in each equation are allowed to change depending on the position of aggregate output growth with respect to an endogenous threshold.

The methodology in Hansen $(1996,2000)$ is used to test the null of linearity and a common threshold for each of the equations. If all the equations in the system are nonlinear but have the same threshold, explanatory variables are split into two different groups according to the value of the common threshold variable. In this case, slope parameters can be efficiently estimated by ordinary least squares (OLS) equation by equation. However, when some equations exhibit no threshold effects and/or a common threshold cannot be imposed, the explanatory variables in each equation are different and OLS no longer provides efficient estimation of the parameters of the system. Our results suggest that a common threshold parameter cannot be imposed in all equations of the system and that the null of linearity can be rejected in all cases except for the inflation equation. Thus, for efficient estimation, the system should be fitted by generalized least squares (GLS). The results from this procedure are then used to obtain reactions to interest rate shocks using the approach of Koop et al. (1996) for 13 manufacturing sectors in the UK.

Our paper combines two different approaches in the empirical literature on monetary transmission. On one hand, it is clearly related to the empirical studies on asymmetries in the transmission of monetary policy mentioned above. But our analysis is also closely connected to Barth and Ramey (2001) and Dedola and Lippi (2005) who, respectively, find significant differential effects of monetary policy shocks across US and OECD industries.

The results here show evidence of both cross-sectional differences and asymmetric responses to monetary shocks for some sectors, dependent on the business cycle. A main feature of asymmetric sectors is that they either have low levels of concentration, or are highly technological in nature. The findings are consistent with both theories that focus on the role of irreversible investment under uncertainty and explanations based on financial restrictions. Under the first theory, economic uncertainty affects investment decisions and the responses of investors to demand shifts. Then asymmetries might be expected to be observed in highly technological industries, as they usually operate in unstable environments. The 
second theory emphasizes the role of credit constraints to explain asymmetries. In this context, it is plausible to anticipate the presence of nonlinearities in small firms as they are more likely to suffer financial restrictions.

The remainder of the paper is organized as follows. Section 2 considers the main problems in extending the traditional VAR approach to a framework that allows for nonlinearities in the different equations of the system. The next section presents the data in the analysis and explains some of their features. Section 4 discusses the methodology of Hansen $(1996,2000)$ for the estimation and testing of threshold models. Based on this approach, for a given equation we can test the null of nonlinearity and make inference on the estimated threshold parameters. This is then used for the specification of a simple system of macroeconomic equations. Section 5 considers the sectoral transmission of monetary policy in the UK. Evidence of asymmetries is mainly found in industries with low concentration. Some concluding remarks follow in Section 6 .

\section{Econometric specification}

Consider a vector autoregression (VAR) for a $n$-dimensional vector, $\mathbf{Y}_{t}$

$$
\mathbf{Y}_{t}=\mathbf{C}+\mathbf{B}_{1} \mathbf{Y}_{t-1}+\ldots+\mathbf{B}_{p} \mathbf{Y}_{t-p}+\mathbf{a}_{t}, E \mathbf{a}_{t} \mathbf{a}_{t}^{\prime}=\mathbf{\Sigma}
$$

where: $p$ is a positive integer; $\mathbf{Y}_{t}$ is a $(n x 1)$ vector of jointly determined variables; $\mathbf{B}_{i}$ is a $(n x n)$ matrix of parameters; and $\mathbf{a}_{t}$ is a vector of zero mean, serially uncorrelated disturbances whose symmetric variance-covariance matrix has typical element $\sigma_{i j}$. Efficient estimates of the parameters of such a system with common degrees can be obtained by running OLS equation by equation.

From model (1) it is not possible to compute the dynamic response function of $\mathbf{Y}_{t}$ to the fundamental shocks in the economy. This because the elements of $\mathbf{a}_{t}$ are, in general, contemporaneously correlated and one cannot presume that they correspond solely to a particular (single) economic shock. To deal with this issue, a structural model is typically considered for economic analysis. Such a model is defined by

$$
\mathbf{A}_{0} \mathbf{Y}_{t}=\boldsymbol{\Lambda}+\mathbf{A}_{1} \mathbf{Y}_{t-1}+\ldots+\mathbf{A}_{p} \mathbf{Y}_{t-p}+\varepsilon_{t}
$$

where $E \varepsilon_{t} \varepsilon_{t}^{\prime}=\mathbf{A}_{0} \boldsymbol{\Sigma} \mathbf{A}_{0}^{\prime}=\mathbf{I}$, an $n$th order identity matrix. The parameter matrices and errors in (1) and (2) are linked by: $\mathbf{B}_{i}=\mathbf{A}_{0}^{-1} \mathbf{A}_{i} ; \mathbf{C}=\mathbf{A}_{0}^{-1} \boldsymbol{\Lambda}$; and $\mathbf{a}_{t}=\mathbf{A}_{0}^{-1} \varepsilon_{t}$ with $\varepsilon_{t}$ being a $(n x 1)$ vector of orthogonal and standarized structural disturbances.

Once consistent estimators of the $\mathbf{B}_{i}$ 's in (1) are obtained, one can estimate $\boldsymbol{\Sigma}$ from the fitted residuals. Information about the matrix $\mathbf{A}_{0}$ is inextricably linked with that in $\boldsymbol{\Sigma}$ via the relationship $\boldsymbol{\Sigma}=\mathbf{A}_{0}^{-1}\left(\mathbf{A}_{0}^{-1}\right)^{\prime}$. However, $\mathbf{A}_{0}$ has $n^{2}$ parameters while the symmetric matrix $\boldsymbol{\Sigma}$ has, at most, $n(n+1) / 2$ distinct elements. Christiano et al. (1999) provide a detailed discussion of this identification problem. In order to identify the structural model one usually imposes a set of linear restrictions across the elements of the individual rows of $\mathbf{A}_{0}$. The 
concomitant order condition, $(i)$, specifies that it is necessary to specify at least $n(n-1) / 2$ restrictions, to get a sufficient condition for identification. Together with this condition, it is necessary, (ii), that the diagonal elements of $\mathbf{A}_{0}$ be positive. However, these conditions are still not sufficient for identification. It is also necessary to ensure, (iii), that a neighbourhood of $\mathbf{A}_{0}$ cannot contain other matrices that fulfil the aforementioned conditions. This is ensured by imposing the additional restriction that the matrix derivative with respect to $\mathbf{A}_{0}$ of the equations defining $\boldsymbol{\Sigma}=\mathbf{A}_{0}^{-1}\left(\mathbf{A}_{0}^{-1}\right)^{\prime}$ is of full rank. By doing this, local identification is established. Global identification must be established on a case by case basis. As discussed by Christiano et al. (1999) sometimes this can be done analytically but, in many circunstances, ad hoc numerical search is necessary to determine if there are different matrices that fulfil the three restrictions $(i)$-(iii) in a neighbourhood of $\mathbf{A}_{0}$. However, if the identification problem only involves systems of linear equations, local identification obtains if, and only if, global identification obtains.

When the model is identified, assuming $\mathbf{Y}_{t}$ to be covariance-stationary, one can use model (2) to compute the responses of variables in $\mathbf{Y}_{t}$ to fundamental shocks in different periods. Thus, computing impulse response functions in the linear case is straightforward for: 1) the parameters of the reduced form model (1) can be estimated efficiently equation by equation by OLS, as the regressors of the different equations are the same; and 2) dynamic response functions of $\mathbf{Y}_{t}$ to fundamental shocks can be obtained analytically from the moving average representation of model (2).

However, these two properties would not hold if the different equations in (1) were nonlinear. In order to see this, consider a specific kind of nonlinearity given by threshold vector autoregressive (TVAR) models ${ }^{1}$. The purpose of such threshold models is to allow for important nonlinearities in conditional expectations without requiring over liberal parameterizations. Moreover, they are relatively easy to specify and estimate the parameters of by comparison with many other nonlinear models for time series. This nonlinear threshold extension of model (1) is given by

$\mathbf{Y}_{t}=\left[\begin{array}{c}y_{1 t} \\ \cdot \\ \cdot \\ \cdot \\ \cdot \\ y_{n t}\end{array}\right]=\left[\begin{array}{cccccc}X_{t}\left(\gamma_{1}\right)^{\prime} & 0 & \cdot & \cdot & 0 \\ 0 & X_{t}\left(\gamma_{2}\right)^{\prime} & \cdot & \cdot & \cdot & \cdot \\ \cdot & \cdot & \cdot & \cdot & \cdot & \cdot \\ \cdot & \cdot & \cdot & \cdot & \cdot & \cdot \\ \cdot & \cdot & \cdot & \cdot & X_{t}\left(\gamma_{n-1}\right)^{\prime} & 0 \\ 0 & \cdot & \cdot & \cdot & 0 & X_{t}\left(\gamma_{n}\right)^{\prime}\end{array}\right]\left[\begin{array}{c}\beta_{1} \\ \cdot \\ \cdot \\ \cdot \\ \cdot \\ \beta_{n}\end{array}\right]+\left[\begin{array}{c}a_{1 t} \\ \cdot \\ \cdot \\ \cdot \\ \cdot \\ a_{n t}\end{array}\right]$

where

$$
\begin{aligned}
X_{t}\left(\gamma_{i}\right)^{\prime} & =\left(X_{t}^{\prime} I\left(q_{t-d} \leq \gamma_{i}\right) \quad X_{t}^{\prime} I\left(q_{t-d}>\gamma_{i}\right)\right), \\
X_{t}^{\prime} & =\left(1, y_{1 t-1}, \ldots, y_{1 t-p}, \ldots, y_{n t-1}, \ldots, y_{n t-p}\right),
\end{aligned}
$$

\footnotetext{
${ }^{1}$ See Tong (1983) for an introduction to threshold models. In threshold models one can allow the relationship to be piece-wise linear but globally nonlinear. Regimes are determined by the position of a given variable with respect to one, or several, thresholds.
} 
$q_{t-d}$ and $\gamma_{i}$ denote the threshold variable $q$ with delay $d$ and the threshold parameter in equation $i$, respectively; $I($.$) is an indicator function; \beta_{i}$ is a $2(n p+1)$ vector of slope parameters in equation $i$. Notice that, unlike the $\mathbf{B}_{i}$ parameters at (1), $\beta_{i}$ has two blocks of size $n p+1$ and each block affects $y_{i t}$ depending on whether $q_{t-d}$ is greater or less than (or equal to) $\gamma_{i}$. Finally, $\mathbf{a}_{t}=\left(a_{1 t}, \ldots, a_{n t}\right)$ is as at (1).

A standard threshold vector autoregressive (TVAR) model can be defined as a special case of (3) where the threshold parameter in the different equations is the same, (i.e. $\gamma_{1}=\gamma_{2}=\ldots=\gamma_{n}$ ). Then, all the regressors in each equation are the same and OLS is an efficient estimator. However, if this is not the case, efficiency can be gained by using GLS.

When a model is linear, impulse response functions can be obtained analytically and are symmetric and independent of the history of the process. However, with threshold models, a different approach needs to be employed because the impact of fundamental shocks depends on the sign and size of the shock as well as on the history of the process. Koop et al. (1996) provide a discussion on this issue and propose a methodology based on Monte Carlo simulation of an equation system. Their suggested procedure is essentially based on the average between the simulation of a nonlinear system with and without imposing a particular fundamental shock in one of the equations. Impulse response functions with standard threshold VARs can be found in Balke (2000) and Atanasova (2003) and the procedure is extended here to permit differential thresholds.

In the remainder of this paper we proceed as follows. First, for a system of macro-equations for the UK economy, we test the null of linearity and, where necessary, estimate the threshold parameter in each of the equations. We also test if a common threshold can be imposed for the whole system. The tests in Hansen (1996) and Hansen (2000) are, respectively, used to address these two questions. It transpires that it is not the case that it is valid to impose a common threshold value across all equations. Consequently, the system parameters are estimated by GLS and the fitted system is used to simulate output reactions to interest rate shocks for thirteen manufacturing sectors in the UK.

\section{Data description}

This section describes some of the important features of the individual time series used in the analysis. Aggregate as well as sectorally disaggregate monthly time series are used. The aggregate series are: the Retail Price Index, $(R P I)^{2}$, as a measure of aggregate price level; the seasonally-adjusted Index of Output of Production Industries, $(O P I)$, as a measure of real activity ${ }^{3}$; the overnight interest rate set by the Bank of England, $\left(r_{0}\right)$, as a measure of monetary stance;

\footnotetext{
${ }^{2}$ Using seasonally adjusted series of $R P I$ does not lead to any material difference in the conclusions of this paper.

${ }^{3}$ There is considerable evidence in the literature that, in the UK, short-term movements in manufacturing output are strongly correlated with movements in other output components; see Salazar et al. (1997) for a discussion.
} 
and the sterling/dollar exchange rate, $(E)$, to measure the external influence in the UK economy.

Disaggregate seasonally-adjusted series of the OPI are used for the following manufacturing sectors:

DA- Manufacture of food products: beverages and tobacco;

DB- Manufacture of textiles and textile products;

DC- Manufacture of leather and leather products;

DD- Manufacture of wood and wood products;

DE- Manufacture of pulp, paper and paper products; publishing and printing;

DG- Manufacture of chemicals, chemical products and man-made fibres;

DH- Manufacture of rubber and plastic products;

DI- Manufacture of other non-metallic mineral products;

DJ- Manufacture of basic metals and fabricated metal products;

DK- Manufacture of machinery and equipment not elsewhere classified;

DL- Manufacture of electrical and optical equipment;

DM- Manufacture of transport equipment; and

DN- Manufacturing not elsewhere classified.

This classification is based on the Standard Industrial Classification, SIC(92). All the series, with the exception of $r_{0}$, are in natural logarithms and cover the period 1972:01-2003:12. They are available from the Office from National Statistics at the following URL: http://www.statistics.gov.uk.

The aggregate series are depicted in Figure 1. Inspection of the figure reveals that price and output series grow smoothly during the period under consideration and interest and exchange rate variables show little tendency to return to their mean. Series in first differences, on the other hand, show regular crossing points and no obvious trend. This suggests that series might be stationary after differencing. The disaggregate output data series are not presented to save space. However, like the aggregate OPI, they are clearly affected by the economic cycles in the UK during the period. More specifically, most of the series evidence the recessions of 1973-1975 and 2001-2003 and exhibit strong growth through the years 1986-1991. After differencing, figures and correlograms of the disaggregated series suggest that they might be stationary.

More formally, we employ the maximum of the forward and reverse Augmented Dickey-Fuller (ADF) tests advocated by Leybourne (1995) to test for unit roots on account of its superior power properties. It is, of course, necessary to choose the number of augmentation lags to account for serial correlation in the basic Dickey-Fuller regressions and this is done using the sequential approach of $\mathrm{Ng}$ and Perron (1995). The results are shown in Table 1.

For series in levels, the unit root null hypothesis cannot be rejected at conventional significance levels in practically all cases, except for the sectors DA and DD and even here the evidence against the null is neither strong nor unambiguous. However, the unit root null can be rejected at the 0.01 level for series in first differences for all variables and so we use all series in first differences in what follows. This approach is also adopted by Balke (2000) and Atanasova 
(2003) and is consistent with the view that monetary policy is neutral in the long run. More specifically, there is a broad consensus among economists that, since it cannot affect output growth, monetary policymakers seek only to affect the fluctuations of cyclical output and inflation.

[INSERT FIGURE 1]

[INSERT TABLE 1]

\section{Estimation of a simple UK macro model}

We begin by specifying of a system of (potential) threshold equations for the UK economy and use the methodology of Hansen $(1996,2000)$ to estimate the parameters of the model and conduct inferences on them. A sectorally disaggregated analysis for manufacturing industry is deferred to the next section.

Macroeconomic models examining monetary policy issues generally involve the minimization of some quadratic loss function by a central banker subject to a linear dynamic system describing the economy; see Svenson (1997) and Clarida et al. (1999) for relevant examples. When the policy instrument is a short-term interest rate, this combination leads to a linear interest rate equation (or Taylor rule), whereby the monetary authority adjusts nominal interest rates to changes in relevant economic variables.

Recently, a number of papers have challenged the linear assumption that underlies the earlier analyses. They can be classified into two different groups. Firstly, authors such as Cukierman and Muscatelli (2003) and Dolado et al. (2000), inter alia, focus their attention on the possibility of asymmetries in the preferences of policy makers with respect to output and/or inflation. When the assumption of a quadratic loss function is substituted for by an asymmetric preference specification, a nonlinear interest rate equation results . Secondly, other authors consider the presence of asymmetries in the structure of the economy. For example, Schaling (1999) and Dolado et al. (2005) study the implications of a nonlinear Phillips curve for monetary policy.

We specify a $(\mathrm{T}) \mathrm{VAR}$ system of macroeconomic equations in which parameter values of the different equations change depending on the position of the business cycle with respect to an endogenous threshold parameter. To capture the fact that different forms of nonlinearites may be present in different equations, the threshold parameter is allowed to be different in the different equations, though a common threshold variable is assumed throughout. The following endogenous variables are used: $\triangle O P I ; \Delta R P I ; \Delta E ;$ and $\Delta r_{0}$. The common number of lags in the four equations is chosen on the basis of conventional specification tests for a linear model. Based on the Schwarz and Akaike 
criteria, the number of lags is set to two. Correlograms of residuals from estimation of the linear specification with two lags show no obvious structure.

Although, these equations have not been derived from a theoretical model, as typically occur in VAR models, it is straightforward to find an economic interpretation for them. For example, the first equation (for $\triangle O P I$ ) relates output growth to interest rate and other fundamentals. This can be though as an aggregate demand curve (AD). The second equation explains inflation as a function of output growth. It can be interpreted in terms of a Phillips curve (PC). The third is an exchange rate equation that extends a closed model to allow for open market considerations (ER) and the fourth defines a Taylor rule set by the monetary authority (TR). This TR reaction function can be interpreted as the result of the minimization of the loss function of the monetary authority subject to the AD, PC and ER curves. In common with all VAR-type systems, ours is backward looking as it only includes current and past information, but not expectations variables. However, this can be reconciled if we assume that expectations about future variables are formed from a combination of current and past information of the variables in the model. In this way, although we cannot interpret the slope parameters in the system economically, an analysis of the effect of structural shocks is still possible.

Given these equations, we make use of Hansen $(1996,2000)$ to deal with two fundamental issues: the estimation of each of the parameters in the aforementioned (T)VAR system; and to test for linearity and for a common threshold parameter in each of the equations.

\subsection{Estimation of a threshold model for a single equation}

The use of stationary series is a basic requirement of the tests in Hansen (1996, 2000) that are applied in this section. Hansen develops the statistical properties of threshold models and shows that, while the threshold model is similar to a changepoint model from a computational point of view, this is not so from a distributional standpoint. However, Hansen (1996) in his Theorem 1 shows that the asymptotic distribution of the threshold estimator takes a similar form to that found in the changepoint literature under his assumptions. As indicated by Hansen (2000), the presence of trends can alter the asymptotic distribution of changepoint tests. Moreover, the asymptotic distribution of such estimates has not yet been developed for trending variables, but this does not concern us here as the first difference data modelled here appear free of trends, both deterministic and stochastic.

In the threshold autoregressive specification for each equation, the threshold variable, $q_{t-d}$, is taken to be one of $\Delta O P I_{t-d}, d=1,2$ in line with the maximum order of lag polynomials set in our analysis. Use of the sum of squares error criterion (compare Hansen, 1997, Table 4) indicates that $q_{t-d} \equiv \Delta O P I_{t-1}$ should be selected. This seems reasonable on economic grounds as it is an obvious business cycle indicator for the recent past. Different potential values of the threshold parameter $\gamma_{i}$ can be specified. However, there are, at most, $T$ possibilities for this value and Hansen (1996) and others have suggested that 
it is inadvisable to use, perhaps, the extreme $15 \%$ at either end of the ranked values of $q_{t-d}$, leaving around $0.7 T$ possible values for $\gamma_{i}$. The possibility that $\gamma_{i}$ may vary across $i=1,2, \ldots, n$ is not excluded here, though previous papers by Balke (2000) and Atanasova (2003) only consider the case of a single threshold value for all equations.

The procedure used by Hansen (1997) is used to estimate the parameters of the $i$ th equation using sequential conditional least squares. This involves computing the least squares estimator of $\beta_{i}$ using

$$
\widehat{\beta}_{i}=\left(\sum_{t=1}^{T} X_{t}\left(\gamma_{i}\right) X_{t}\left(\gamma_{i}\right)^{\prime}\right)^{-1}\left(\sum_{t=1}^{T} X_{t}\left(\gamma_{i}\right) y_{i t}\right)
$$

for a given value of $\gamma_{i}$. We obtain residuals of the equation by $\widehat{a}_{i t}\left(\gamma_{i}\right)=y_{i t}-$ $\widehat{\beta}_{i}^{\prime} X_{t}\left(\gamma_{i}\right)$, and compute the residual variance as

$$
\widehat{\sigma}_{i T}^{2}\left(\gamma_{i}\right)=\frac{1}{T} \sum_{t=1}^{T} \widehat{a}_{i t}\left(\gamma_{i}\right)^{2} .
$$

Obviously, small sample adjustments to account for degrees of freedom could be incorporated in the error variance estimator.

The OLS estimator of $\gamma_{i}$ is the value that minimizes (5):

$$
\widehat{\gamma}_{i}=\arg \min _{\gamma \in \Gamma} \widehat{\sigma}_{i T}^{2}\left(\gamma_{i}\right)
$$

For this minimization $\gamma_{i}$ is assumed to be restricted to a bounded set $\Gamma=$ $\left(\begin{array}{ll}\underline{\gamma} & \bar{\gamma}\end{array}\right)$, where, as suggested above, $\Gamma$ was selected a priori to contain $70 \%$ of the observations, trimming the bottom and top 15\% quantiles of the threshold variable; see Hansen (1997).

Results of the estimation of the slope parameters for each of the reduced form equations are economically uninteresting and not reported here.

\subsection{Inference on the parameters of the model}

Once the parameters are estimated two issues need to be addressed: (i) to test for linearity of the slope parameters (i.e. no evidence of change in slope and hence no threshold); and (ii) inference about any threshold parameter, $\gamma_{i}$. With regard to the test of linearity, as pointed by Hansen (1996), the Wald statistic for such a test does not follow a standard distribution. This is because $\gamma_{i}$ is not identified under the null hypothesis. However, appropriate asymptotic critical values can be found by bootstrap methods using the procedure described in Hansen (1996, Section 3).

Table 2 exhibits the Wald statistic to test for linearity in each of the equations. The results show that it is possible to reject the null of linearity in two cases at conventional significance levels, but not in the cases of the $\mathrm{PH}$ and $\mathrm{AD}$ curves. The case of the $\mathrm{AD}$ equation is somewhat problematic, as the $p$ value of the statistic is 0.08 . To deal with this issue, we actually developed the 
subsequent analysis in both situations (with a linear and with a nonlinear AD equation), but no important differences between these two cases were found. Given that the case with a nonlinear AD curve is a more general specification, this is the case reported here.

\section{[INSERT TABLE 2]}

Proceeding by acknowledging the existence of a threshold parameter in three of the equations, the next task is to test if a common threshold parameter applies to the three nonlinear equations. It is also useful to test $H_{0}: \gamma_{i}=0$ for each of the nonlinear equation as this is the (exogenous) threshold typically imposed in many papers in the literature on real business cycle. To do this we use the methodology proposed by Hansen (2000). He establishes an asymptotic distribution for the least squares estimator of the threshold that is free of nuisance parameters under fairly general conditions. A suitable likelihood ratio statistic $L R_{i t}\left(\gamma_{0}\right)$ for testing the null hypothesis $H_{0}: \gamma=\gamma_{0}$ in the $i$ th equation of the system is given by

$$
L R_{i T}\left(\gamma_{0}\right)=T\left(\frac{\widehat{\sigma}_{i T}^{2}\left(\gamma_{0}\right)-\widehat{\sigma}_{i T}^{2}\left(\widehat{\gamma}_{i}\right)}{\widehat{\sigma}_{i T}^{2}\left(\widehat{\gamma}_{i}\right)}\right)
$$

with rejection of $H_{0}$ being warranted for sufficiently large values of the calculated test statistic.

Theorem 2 in Hansen (2000) shows that

$$
L R_{i T}\left(\gamma_{0}\right) \stackrel{d}{\rightarrow} \varsigma
$$

where

$$
\varsigma=\max _{s \in R}[2 W(s)-|s|]
$$

and $W(s)$ is defined as a two-sided Brownian motion on the real line such that

$$
W(s)=\left\{\begin{array}{cc}
W_{1}(-s) & s<0 \\
0 & s=0 \\
W_{2}(s) & s>0
\end{array},\right.
$$

with $W_{1}(s)$ and $W_{2}(s)$ being two independent standard Brownian motions on $[0, \infty]$. The distribution function of $\varsigma$ is a standard result and is given by $P(\varsigma \leq$ $x)=\left(1-e^{-x / 2}\right)^{2}$. Critical values can be obtained from the direct inversion of the distribution function and the $p$-value of an observed test statistic can readily be calculated.

Hansen (2000) also proposes the construction of confidence regions based on the likelihood statistic $L R_{i T}(\gamma)$. To obtain the desired asymptotic confidence region at level as $1-\alpha$, let $c_{\varsigma}(1-\alpha)$ be the $(1-\alpha)$-level critical value for $\varsigma$. Then

$$
\widehat{\Gamma_{i}}=\left\{\gamma_{i}: L R_{i T}\left(\gamma_{i}\right) \leq c_{\varsigma}(1-\alpha)\right\}
$$


provides an asymptotic $(1-\alpha)$-level confidence region for $\gamma_{i}$. Typical values for $\alpha$ are, of course, $0.01,0.05$ and 0.1 .

Table 3 shows the estimation of the threshold, $\widehat{\gamma}_{i}$, and a $95 \%$ confidence region $(\alpha=0.05)$ for each of the equations. Note that the estimated threshold parameter clearly differs across equations.

\section{[INSERT TABLE 3]}

The value of the likelihood ratio test statistics, $L R_{i T}(\gamma)$, for the imposition the threshold estimated in one of the equations in all the other nonlinear equations of the system are given in Table 4. This table also includes a test for a threshold equal to zero in each of the equations. Notice that at the 0.01 significance level we only fail to reject imposing the estimated threshold of the $\mathrm{E}$ in the TR equation.

\section{[INSERT TABLE 4]}

It can be concluded from this analysis that threshold estimates are different across the different equations of the system and only the Phillips curve does not show evidence of nonlinearity. The failure to detect asymmetries in the Phillips curve is not uncommon in the literature; see Laxton et al (1999) for a discussion. Therefore the system of equations can be regarded as a system of seemingly unrelated equations where one equation is linear and each of the nonlinear equations has its own threshold.

\section{Sectoral transmission of monetary policy shocks in the UK}

This section considers an additional endogenous variable for sectoral output growth to obtain a new system of equations that includes a particular sectoral growth variable and the macroeconomic variables already considered in the previous section. Thus there are as many systems of equations as number of manufacturing sectors in the analysis. Each of the systems is used to estimate sectoral output reactions to interest rate shocks using the impulse response function procedure in Koop et al (1996). The structural models are identified by imposing a recursiveness assumption. This scheme is simple and has seen widespread use in previous studies. In this analysis we use the causal ordering $\triangle O P I, \triangle R P I, \Delta E, \Delta r_{0}$ and, finally, the relevant sectoral output growth. This ordering assumes that the overnight interest rate does not have a contemporaneous impact on the other macroeconomic variables, but that these variables do affect the behaviour of monetary policy makers contemporaneously. For example 
Bernanke and Blinder (1992) and Wright (2002) both have recursive structures with similar forms. However, investigations not reported here indicate that the use of alternative plausible orderings makes little difference.

Equations in the reduced form model (3) are estimated with two lags as in the previous case. Each of the sectoral systems comprises the four macroequations specified in Section 4 and an additional equation that relates sectoral output growth to both its own lagged values and the different (lagged) macrovariables. This specification is economically plausible, since it is reasonable to argue that macro-economic variables are affected by aggregate information but not by sectoral output growth. For example, when central bankers set an overnight interest rate, they are concerned with fluctuations in aggregate output rather than output variations in a specific sector. The specification differs from standard VAR models that impose identical explanatory variables in all the equations. However, this presents no difficulties in this context as the system parameters are estimated by GLS.

As in the previous section, we first test the null of linearity in each of the sectoral equations and the results of the tests can be found in Table 5. Broadly speaking, the null of linearity cannot be rejected in highly concentrated sectors. More specifically, the null of linearity can only be rejected in certain sectors with a market share of the 10 largest firms in the sector at a level below the average, except for DG (Manufacture of chemicals, chemical products and manmade fibres). A plausible explanation may be that low concentrated sectors are dominated by small firms and often they are likely to be affected by financial constraints and economic uncertainty in downturn periods; these results are consistent with Canepa and Stoneman (2002). They show that the impact of financial constraints is bigger in high technological sectors and in those with small firms. Furthermore, they explicitly mention Chemicals and Machinery as two technological sectors. Next we test if the estimated thresholds in the macro-equations can be imposed in the different equations of the system but the null was rejected in all cases; see Table 6 for details.

\section{[INSERT TABLE 5]}

\section{[INSERT TABLE 6]}

Once the threshold parameters are estimated (they are given in the leftmost column of figures in the table), the slope parameters in the thirteen sectoral systems of equations are estimated by feasible generalized least square. With each system we estimate the sectoral reactions to unexpected shocks in the interest rate equation using the approach in Koop et al (1996). A more detailed explanation of this procedure can be found in the Appendix. In the simulations some of the equations are linear, e.g. the Phillips curve and output growth in some of the sectors, and each of the nonlinear equations has its own threshold. Unsurprisingly, we do not find evidence of asymmetry in the linear sectors. 
Sectoral reactions for the nonlinear sectors are of interest. Figure 2 shows cumulative reactions to an interest rate shock in low growth and high growth periods. High and low growth periods are classified according to the position of $\triangle O P I_{t}$ [with respect to the threshold parameter in the TR curve when thelshock occurs. However, these reactions depend asymmetrically on the size and sign of the shock in that asymmetries become more evident the smaller is the size of the shock and negative interest rate shocks have a bigger impact on output than positive ones. The figures presented are for the case where the size of shock is 25 basis points as this is a standard interest rate movement by the Bank of England for the period under analysis. However, the substantive conclusions of the paper remain unaltered when shocks of different size and sign are used.

It can be seen that an increase in interest rate has a negative effect on sectoral output growth in practically all cases which is consistent with economic theory ${ }^{4}$. A feature of these reactions is that there are important asymmetries depending on the business cycle in two sectors: Manufacture of textiles and textile products; and Manufacture Not Elsewhere Classified and, in these industries, reactions are stronger when the shock occurs in the expansion period.

\section{[INSERT FIGURE 2]}

At least two alternative theories may be helpful in explaining the results. First, the fact that sectors that are more likely to suffer financial constraints are more sensitive to monetary shocks in the low growth period compared to the high growth period is consistent with the arguments of Dale and Haldane (1995). They compare output reactions to monetary shocks in personal and corporate sectors in the UK finding stronger reactions for the corporate sector. They suggest that financial restrictions can weaken the effects of monetary policy if they result in the marginal interest rates on loans becoming sticky in response to official rate changes. Our results also seem to be consistent with the model in Abel and Eberly (1999) which shows that uncertainty weakens the response of investment to demand shocks. It may be the case that periods of low economic growth are typically associated with higher uncertainty and technological sectors and low market share sectors are more likely to be affected by this economic uncertainty.

\section{Concluding remarks}

This paper reports and analyzes the asymmetric effects of monetary policy in 13 industrial sectors of the UK economy. Unlike recent research on multivariate threshold systems, we do not impose threshold parameters in the different equations to be the same. The use of econometric tests proposed by Hansen (1996,

\footnotetext{
${ }^{4}$ The only exception to this is in sector Manufacture of Machinery and Equipment Not Elsewhere Classified. One reason may be that reactions in this sector are very erratic in the first few months.
} 
2000) forms an important part of our approach. We find the null of linearity cannot be rejected for every equation in the system. In particular, there is insufficient evidence to reject the null in the equation for inflation and in some of the industrial sectors. Often these sectors are highly concentrated. Based on the results of using the test in Hansen (2000), an exogenous threshold equal to zero cannot be imposed in any of the equations. This is a relevant result as many papers in the previous literature impose this exogenous threshold to analyze different types of asymmetries. Finally, in general, a common threshold cannot be imposed for all the equations in the system. These results justify the use of systems of simultaneous equations that do not require the same specification for each of the constituent equations.

The estimated the systems of simultaneous equations are used to simulate the effect of unexpected interest rate shocks on sectoral output. Our results provide evidence of both cross-sectional differences across industries and asymmetric effects of monetary shocks for some sectors. We find that industries with low levels of concentration (termed market share and measured by the share of the largest 10 firms in an industry), such as Manufacture of textiles and textile products and Manufacture not elsewhere classified, are more prone to be affected differently by interest rate shocks depending on the business cycle. The results strongly support the use of a sectoral approach for the analysis of monetary transmission as these asymmetries for specific sectors could be masked in an aggregate approach. 


\section{References}

Abel, A.B. and J.C. Eberly, 1999, The effects of irreversibility and uncertainty on capital accumulation, Journal of Monetary Economics, 44, 339-377.

Atanasova, C., 2003, Credit market imperfections and business cycle dynamics: a nonlinear approach, Studies in Nonlinear Dynamics and Econometrics, 7, Issue 4, Article 5.

Ball, L. and G. Mankiw, 1994, Asymmetric price adjustment and economic fluctuations, Economic Journal, 104, 247-61.

Balke, N., 2000, Credit and economic activity: credit regimes and nonlinear propagation of shocks, Review of Economics and Statistics, 82, 344-349.

Barth, M.J., and V.A. Ramey, 2001, The cost channel of monetary transmission, in: NBER Macroeconomic Annuals 2001B, eds., B. Bernanke and K. Rogoff (MIT Press, Cambridge, MA) 199-240.

Bernanke, B.S. and A.S. Blinder, 1992, The federal funds rate and the channels of monetary transmission, American Economic Review, 82, 901-921.

Bernanke, B.S, M. Gertler, M., and S. Gilchrist, 1996, The Financial accelerator and the flight to quality, Review of Economics and Statistics, 18, 1-15.

Canepa, A. and P. Stoneman, 2002, Financial constraints on innovation: a European cross country study, Working Paper No 02-11, The United Nations University, Maastricht.

Christiano, L.J., M. Eichenbaum and C. Evans, 1999, Monetary shocks: What we have learned and to what end, in: Handbook of macroeconomics, eds., J.B.Taylor, M.Woodford, Volume A, North-Holland, 65-148.

Clarida, R., J., Gali and M. Gertler, 1999, The science of monetary policy: a new Keynesian perspective, Journal of Economic Literature, 37, 1661-1707.

Cukierman, A. and A. Muscatelli, 2002, Do central banks have precautionary demands for expansions and for price stability?, Working paper, University of Glasgow.

Dale, S. and A.G. Haldane, 1995, Interest rates and the channels of monetary transmission: some sectoral estimates, European Economic Review, 39, 1611-26.

Dedola, L. and F. Lippi, 2005, The monetary transmission mechanism: evidence from industries of five OECD countries, European Economic Review, forthcoming.

Dolado, J.J, R. María Dolores, and M. Neveira, 2000, Asymmetries in monetary policy: evidence of four central banks, CEPR Discussion Paper n. 2441.

Dolado, J.J., R. María Dolores and M. Neveira, 2005, Are monetary-policy reaction functions asymmetric?: the role of nonlinearity in the Phillips cure, European Economic Review, 49, 485-503.

Greenwald, B. and J. Stiglitz, 1993, Financial market imperfections and business cycles, Quarterly Journal of Economics, 108, 77-114.

Hamilton, J.D., 1994, Time Series Analysis, Princeton University Press.

Hansen, B.E., 1996, Inference when a nuisance parameter is not identified under the null hypothesis, Econometrica, 64, 413-30.

Hansen, B.E, 1997, Inference in TAR Models, Studies in Nonlinear Dynamics and Econometrics, 2, Issue 1, Article 1. 
Hansen, B.E., 2000, Sample splitting and threshold estimation, Econometrica, $68,575-603$.

Kiyotaki, N. and J. Moore, 1997, Credit cycles, Journal of Political Economy, 105, 211-48.

Koop, G., M.H. Pesaran. and S.M. Potter, 1996, Impulse response analysis in nonlinear multivariate models, Journal of Econometrics, 74, 119-147.

Laxton, D., D.Rose and D. Tambakis, 1999, The case for asymmetry in the U.S. Phillips curve, Journal of Economic Dynamics and Control, 23, 1459-1485.

Leybourne, S.J., 1995, Testing or unit roots using forward and reverse DickeyFuller regressions, Oxford Bulletin of Economics and Statistics, 57, 559-571.

Ng, S. and P. Perron, 1995, Unit root tests in ARMA Models with datadependent methods for the selection of the truncation lag, Journal of the American Statistical Association, 429, 268-281.

Salazar, E., R. Smith, M.Weale and S.H. Wright, 1997, A monthly indicator of GDP, National Institute Economic Review, 161, 84-90.

Schaling, E., 1999, The non-linear Phillips curve and inflation forecasting targeting, Working paper No. 98, Bank of England.

Sims, C.A., 1980, Macroeconomic and reality, Econometrica, 48, 1-48.

Sims, C.A., 1992, Interpreting the macroeconomic time-series facts: the effects of monetary policy, European Economic Review, 36, 975-1011.

Svenson, L. E. O., 1997, Inflation forecasting targeting: implementing and monitoring inflation targets, European Economic Review, 41, 1111-1146.

Tong, H., 1983, Threshold Models in Nonlinear Time Series Analysis, Lecture Notes in Statistics, 21, Berlin:Springer.

Wright, S., 2002, Monetary policy, nominal interest rate, a long-horizon inflation uncertainty, Scottish Journal of Political Economy, 40, 61-90. 


\section{Appendix}

\section{Estimation of the impulse-response function}

This appendix describes the procedure to estimate the impulse-response function along the lines of Atanasova (2003). In this paper, the procedure is considered for the analysis of sectoral output reactions to interest rate shocks. The steps followed in order to obtain the (generalized) impulse-response function are described below.

- The first step is to estimate the parameters for the different equations in the nonlinear system. This is done using Hansen (1997). Then, conditional on the threshold parameters chosen, slope parameters in the system of equations are computed by iterative feasible generalized least squares.

- Pick a starting value $w_{t}$. If we denote output growth in sector $i$ at time $t$ as $s_{i t}$ then $w_{t}$ can be defined as $w_{t}=\left(\Delta O P I_{t}, \Delta R P I_{t}, \Delta E_{t}, \Delta r_{0 t}, s_{i t}\right)^{\prime}$. This vector is used to initiate the simulation of the sectoral (T)VAR system in the subsequent steps.

- Pick a sequence of of 5-dimensional shocks. This is done by using the inverse of a Cholesky factorization of the estimated covariance matrix. This transforms the estimated errors of the nonlinear model in contemporaneous orthogonal shocks $\left(\widehat{\varepsilon}_{t}\right)$. That is, $\widehat{\varepsilon}_{t}=P^{-1} \widehat{a}_{t}$, where $\widehat{a}_{t}$ are the residuals of the model and $P$ is the lower triangular Cholesky decomposition of the residuals. Draw a sequence of these shocks randomly and independently (with replacement) which is denoted by $\left\{\widehat{\varepsilon}_{1}, \widehat{\varepsilon}_{2}, \ldots, \widehat{\varepsilon}_{h}\right\}$, where $h=1, \ldots, H$ . Here $h$ represents the time horizon in the simulation and $H$ is the number of months we want to simulate after the shock occurs. The residuals thus obtained are recovered by $\widehat{a}_{t}=P \widehat{\varepsilon}_{t}$. We also consider the same sequence of shocks, except that a shock of size 0.25 is imposed on the fourth element of $\widehat{\varepsilon}_{1}$. The reason for this is that we need to analyze the effects of a shock in $\Delta r_{0 t}$. The sample of residuals recovered is denoted $\widehat{a}_{t}^{*}$.

- Simulate the evolution of $Y_{t+h}$ using $w_{t}$ and one sample of residuals $\widehat{a}_{t+h}$. The values thus obtained were denoted by $Y_{t+h}\left(w_{t}, \widehat{a}_{t+h}\right), h=1, \ldots, H$.

- Then simulate the evolution of $Y_{t+h}$ using $w_{t}$ and one sample of residuals $\widehat{a}_{t+h}^{*}$. The values thus obtained were denoted by $Y_{t+h}\left(w_{t}, \widehat{a}_{t+h}^{*}\right), h=$ $1, \ldots, H$.

- The last two steps are repeated $R$ times for each of the samples to form an average of each individual component. 


$$
\begin{aligned}
& \bar{Y}_{t+h}\left(w_{t}, \widehat{a}_{t+h}\right)=\frac{1}{R} \sum_{j=1}^{R} Y_{t+h}^{j}\left(w_{t}, \widehat{a}_{t+h}^{(j)}\right), j=1, \ldots, R \text { and } h=1,2, \ldots, H \\
& \bar{Y}_{t+h}\left(w_{t}, \widehat{a}_{t+h}^{*}\right)=\frac{1}{R} \sum_{j=1}^{R} Y_{t+h}^{j}\left(w_{t}, \widehat{a}_{t+h}^{*(j)}\right), j=1, \ldots, R \text { and } h=1,2, \ldots, H
\end{aligned}
$$

where $\widehat{a}_{t+h}^{(j)}$ denotes the (5-dimensional) residual used in the $j t h$ replication at time $t+h$ and $Y_{t+h}^{j}\left(w_{t}, \widehat{a}_{t+h}^{(j)}\right)$ the values of $Y_{t+h}$ obtained using the resicuals of the $j t h$ replication. $\widehat{a}_{t+h}^{*(j)}$ and $Y_{t+h}^{j}\left(w_{t}, \widehat{a}_{t+h}^{*(j)}\right)$ are defined in a similar way for the case when an interest rate shock of 25 basis points is imposed at period $t$.

- We took the difference of the two averages to form a Monte Carlo estimate of the reaction function to a monetary shock.

- This process was repeated $B$ times and the estimate reaction is an average of these. We set: $H$ at $60 ; B$ at 500 ; and $R$ at 500 . 
Table 1. ADF Unit root test of Leybourne (1995).

\begin{tabular}{|c|c|c|c|c|c|c|}
\hline \multirow[t]{2}{*}{ Series } & \multirow[t]{2}{*}{$\mathbf{n}^{(\mathrm{I})}$} & \multirow[t]{2}{*}{$\mathbf{p}^{(\text {II) }}$} & \multicolumn{2}{|c|}{ Series in levels } & \multicolumn{2}{|c|}{ Series in first differences } \\
\hline & & & $\mathrm{ADF}_{\text {tmax }}(\mathrm{p})$ & $\mathrm{ADF}_{\max }(\mathbf{p})$ & $\mathrm{ADF}_{\text {tmax }}(\mathbf{p})$ & $\mathrm{ADF}_{\max }(\mathrm{p})$ \\
\hline OPI & 375 & 9 & -2.91 & -0.09 & $-5.80(* *)$ & $-5.74(* *)$ \\
\hline RPI & 372 & 12 & -1.11 & -1.32 & $-4.41(* *)$ & $-2.57(* *)$ \\
\hline $\boldsymbol{R}_{0}$ & 381 & 3 & -1.97 & -2.02 & $-12.19(* *)$ & $-12.12(* *)$ \\
\hline$E$ & 380 & 4 & -2.35 & -1.27 & $-9.62(* *)$ & $-9.55(* *)$ \\
\hline$D A$ & 372 & 12 & $-3.43(*)$ & 0.01 & $-6.34(* *)$ & $-6.29(* *)$ \\
\hline$D B$ & 381 & 3 & -1.15 & 1.01 & $-18.26(* *)$ & $-18.15(* *)$ \\
\hline$D C$ & 374 & 10 & -1.80 & 0.65 & $-5.45(* *)$ & $-5.29(* *)$ \\
\hline$D D$ & 375 & 9 & -2.65 & $-2.62(*)$ & $-5.69(* *)$ & $-5.66(* *)$ \\
\hline$D E$ & 376 & 8 & -2.27 & -1.02 & $-5.70(* *)$ & $-5.70(* *)$ \\
\hline$D G$ & 378 & 6 & -2.89 & -0.43 & $-8.12(* *)$ & $-8.13(* *)$ \\
\hline$D H$ & 372 & 12 & -2.83 & -0.81 & $-3.60(*)$ & $-3.59(* *)$ \\
\hline DI & 377 & 7 & -2.08 & -2.08 & $-8.13(* *)$ & $-8.15(* *)$ \\
\hline$D J$ & 374 & 10 & -2.61 & -2.23 & $-5.54(* *)$ & $-5.56(* *)$ \\
\hline$D K$ & 375 & 9 & -1.25 & -1.73 & $-6.42(* *)$ & $-6.42(* *)$ \\
\hline$D L$ & 374 & 10 & -2.79 & -0.34 & $-4.61(* *)$ & $-4.60(* *)$ \\
\hline$D M$ & 372 & 12 & -1.44 & -1.18 & $-6.58(* *)$ & $-6.55(* *)$ \\
\hline$D N$ & 382 & 2 & -1.55 & -1.20 & $-23.30(* *)$ & $-23.33(* *)$ \\
\hline
\end{tabular}

$A D F_{\text {tmax }}(p)$ and $A D F_{\text {max }}(p)$ denote the maximum Augmented Dickey Fuller tests applied to both forward and reverse data realization in a regression with and without trend respectively.

(I) $\quad n$ indicates the number of observations after adjusting endpoints.

(II) $p$ indicates the number of lags.

$(* *),(*)$ denote rejection of the null hypothesis at the 0.01, 0.05 significance levels respectively. 
Table 2. Test for Linearity.

\begin{tabular}{|l|r|r|r|r|}
\hline & \multicolumn{1}{|c|}{ AD } & \multicolumn{1}{c|}{ PH } & \multicolumn{1}{c|}{ E } & \multicolumn{1}{c|}{ TR } \\
\hline $\begin{array}{l}\text { Linearity } \\
\text { test }\end{array}$ & 25.05 & 16.23 & 33.45 & 38.12 \\
\hline p-value & $(0.083)$ & $(0.54)$ & $(0.002)$ & $(0.003)$ \\
\hline
\end{tabular}

This table shows the test for linearity in each of the macro-equations. We use the procedure developed by Hansen (1996).

Table 3. Estimation of Threshold Parameters and Threshold Region with a confidence coefficient of 95\%.

\begin{tabular}{|c|c|c|c|}
\hline Equation & $\hat{\gamma}$ & $\hat{\gamma}_{\max }$ & $\hat{\gamma}_{\text {min }}$ \\
\hline $\boldsymbol{A D}$ & -0.007 & -0.001 & -0.008 \\
\hline $\boldsymbol{E}$ & 0.0014 & 0.0029 & 0.001 \\
\hline $\boldsymbol{T R}$ & 0.0122 & 0.013 & 0.011 \\
\hline
\end{tabular}

This table shows the estimation of the threshold parameter $\gamma$ and the maximum and minimum value of $\gamma$ in a confidence region at the 50\% following Hansen (2000).

Table 4. Likelihood Ratio Test of Imposing Different Thresholds in each of the Nonlinear Equations.

\begin{tabular}{|l|l|c|c|c|}
\hline Equation & $L R_{i T}\left(\hat{\gamma}_{A D}\right)$ & $L R_{i T}\left(\hat{\gamma}_{E}\right)$ & $L R_{i T}\left(\hat{\gamma}_{T R}\right)$ & $L R_{i T}(0)$ \\
\hline AD & 0.00 & $13.43(* *)$ & $11.33(* *)$ & $14.14(* *)$ \\
\hline E & $15.95(* *)$ & 0.00 & $13.38(* *)$ & $9.30(*)$ \\
\hline TR & $21.93(* *)$ & 5.44 & 0.00 & $11.27(* *)$ \\
\hline
\end{tabular}

This table shows the likelihood ratio test of imposing each of the thresholds estimated in the different nonlinear macro- equations to the rest of equations.

* (**) denotes rejection at the 0.05 (0.01) significance level. 
Table 5. Test for linearity in sectoral output growth Sectoral Output Growth Equation.

\begin{tabular}{|l|l|l|l|l|l|l|l|}
\hline Sector & DA & DB & DC & DD & DE & DG & DH \\
\hline Wald Statistic & 19.34 & $\begin{array}{l}28.24 \\
(*)\end{array}$ & 20 & 17.15 & $\begin{array}{l}45.98 \\
(* *)\end{array}$ & $\begin{array}{l}37.13 \\
(* *)\end{array}$ & $\begin{array}{l}41.32 \\
(* *)\end{array}$ \\
\hline Market Share $^{(\mathbf{I})}$ & 0.42 & 0.21 & 0.41 & 0.25 & 0.19 & 0.44 & 0.16 \\
\hline Sector & DI & DJ & DK & DL & DM & DN & \\
\hline Wald Statistic & 25.98 & $\begin{array}{l}41.80 \\
(* *)\end{array}$ & $\begin{array}{l}30.66 \\
(*)\end{array}$ & 17.48 & 20.78 & $\begin{array}{l}28.16 \\
(*)\end{array}$ & \\
\hline Market Share $^{(\mathbf{I})}$ & 0.45 & 0.31 & 0.29 & 0.50 & 0.69 & 0.17 & \\
\hline
\end{tabular}

This table shows the test for linearity in each of the industrial equations following the approach indicated by Hansen (1996). (**) denotes rejection at the 0.05 (0.001) significance level

(I) Market Share indicates the market share of the 10 biggest firms in the industry. Source: Annual Census of Production (1993). 
Table 6. Estimation of the threshold parameter for the sectoral equation and test for imposing different thresholds in this equation.

\begin{tabular}{|l|l|l|l|l|l|}
\hline & $\hat{\gamma}$ & $L R_{i T}\left(\hat{\gamma}_{A D}\right)$ & $L R_{i T}\left(\hat{\gamma}_{E}\right)$ & $L R_{i T}\left(\hat{\gamma}_{T R}\right)$ & $L R_{i T}(0)$ \\
\hline DB & -0.007 & 1.66 & $15.18(* *)$ & $15.26\left(^{* *}\right)$ & $16.97\left(^{* *}\right)$ \\
\hline DE & -0.011 & 7.15 & 6.09 & $17.81\left(^{* *}\right)$ & $9.01\left(^{*}\right)$ \\
\hline DG & -0.010 & 4.92 & 6.59 & 4.09 & 6.89 \\
\hline DH & -0.004 & $10.10\left(^{*}\right)$ & $16.25(* *)$ & $28.78\left(^{* *}\right)$ & $13.46\left(^{* *}\right)$ \\
\hline DJ & -0.006 & $13.23(* *)$ & $25.13(* *)$ & $22.80\left(^{* *}\right)$ & $27.07\left(^{* *}\right)$ \\
\hline DK & 0.009 & 6.24 & $14.48(* *)$ & $7.45\left(^{*}\right)$ & $16.22\left(^{* *}\right)$ \\
\hline DN & 0.001 & $19.71(* *)$ & 0.71 & 4.84 & 4.92 \\
\hline
\end{tabular}

This table shows the threshold estimated in each of the sectoral equations and the likelihood ratio test of imposing the threshold estimated in each of the nonlinear macro-equations to the nonlinear industrial equations.

* (**) denotes rejection at the 0.05 (0.001) significance level. 
Figure 1. Aggregate series in levels and first differences

Overnight Interest Rate. Series in levels.

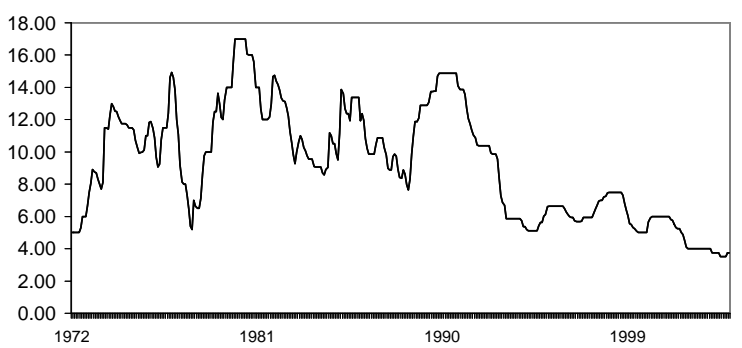

Sterling for one dolar. Series in levels.

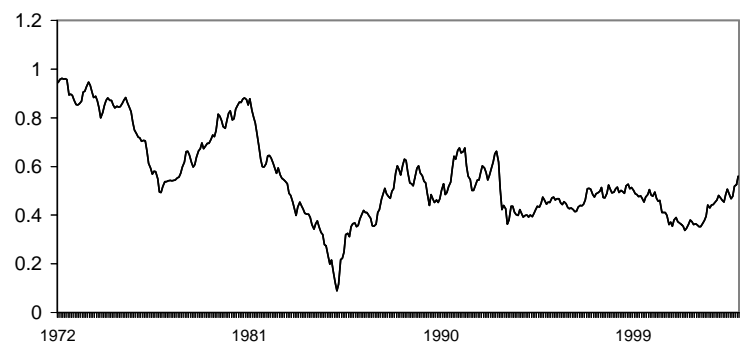

Overnight Interest Rate. Series in first differences.

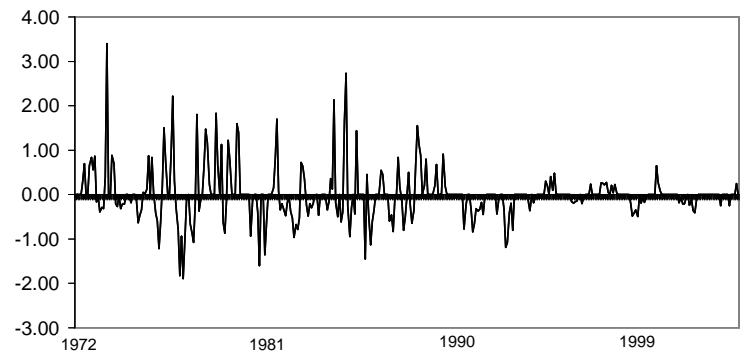

Sterling for one dolar. Series in first differences.

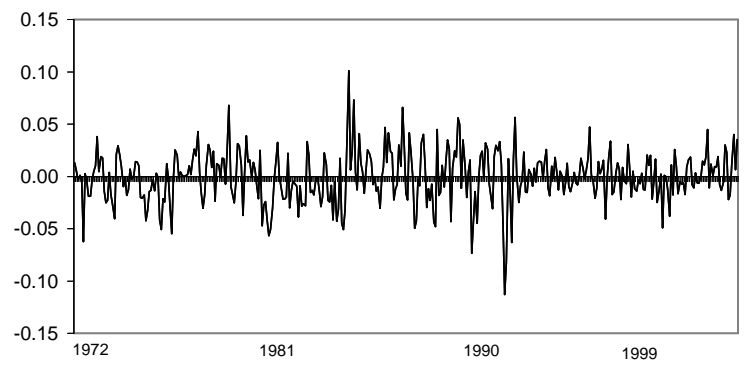

Retail Price Index. Series in levels.

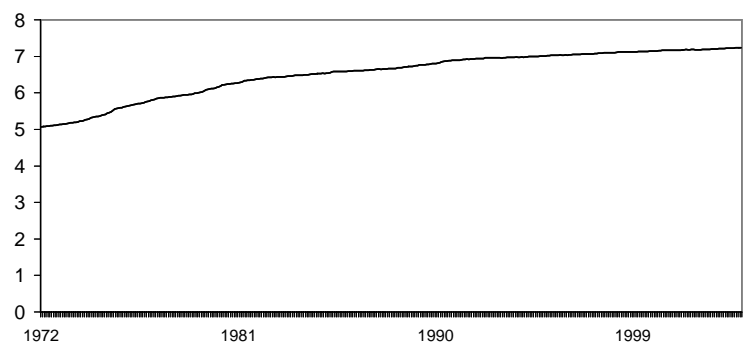

Output of Production Index. Series in levels.

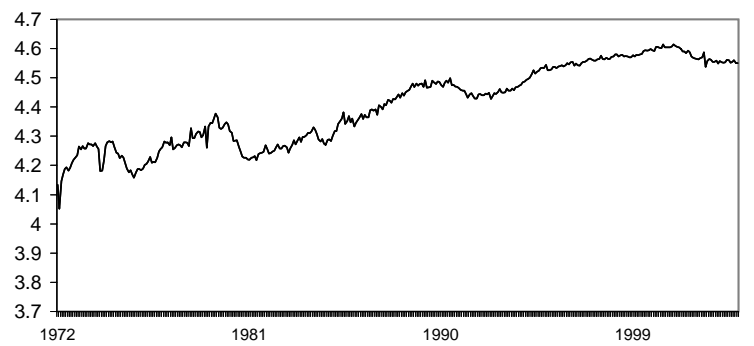

Retail Price Index. Series in first differences.
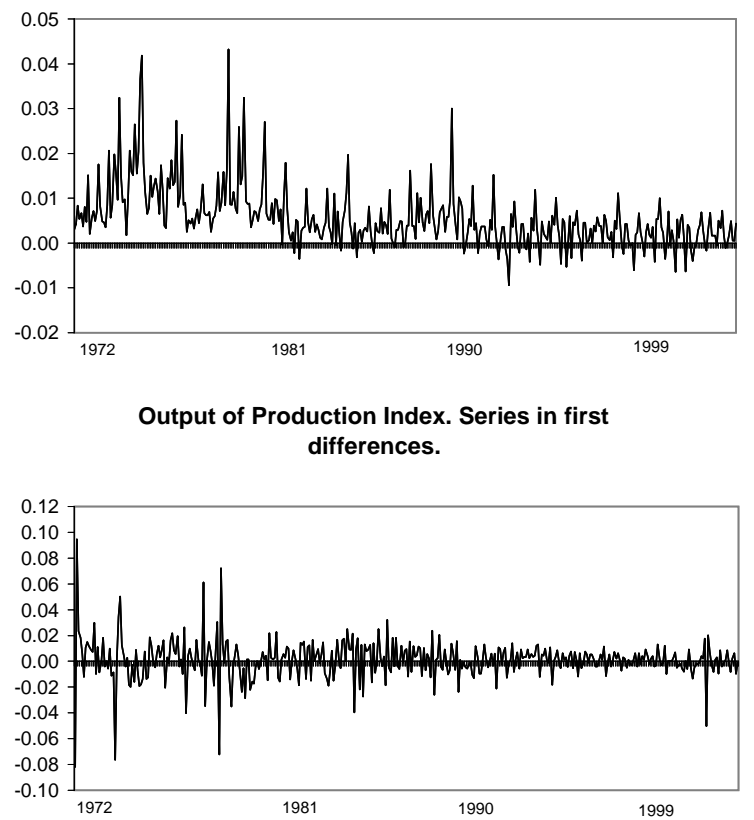
Figure 2a. Sectoral Reactions to Positive Interest Rate Shocks ${ }^{(1)}$

Manufacture of Textile and Textile Products

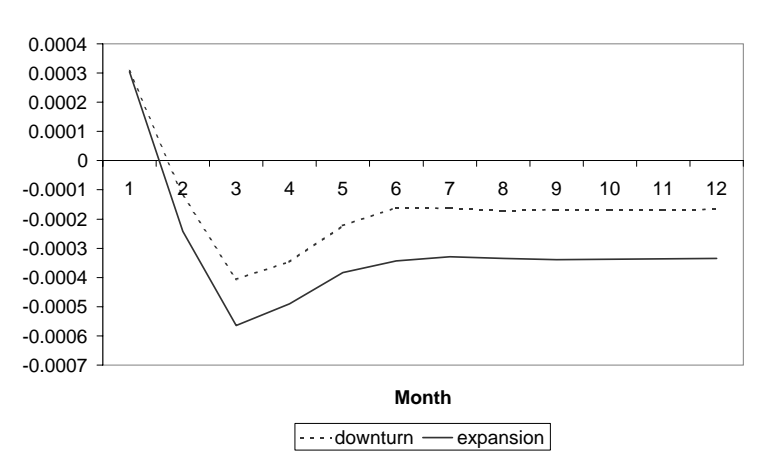

Manufacture of Chemicals, Chemical Products and Man-Made Fibres

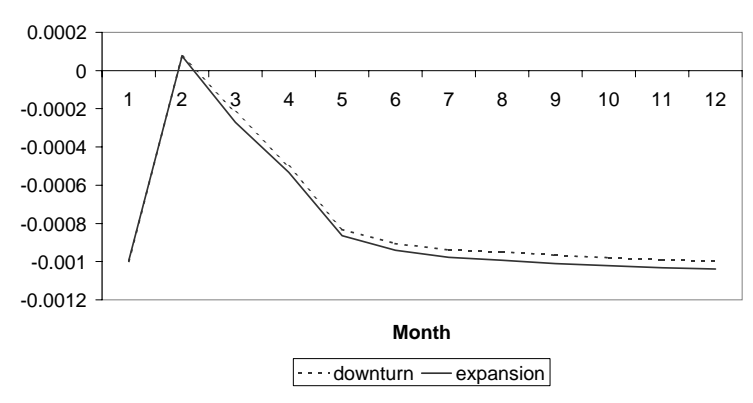

Manufacture of Pulp, Paper and Paper Products; Publishing and Printing

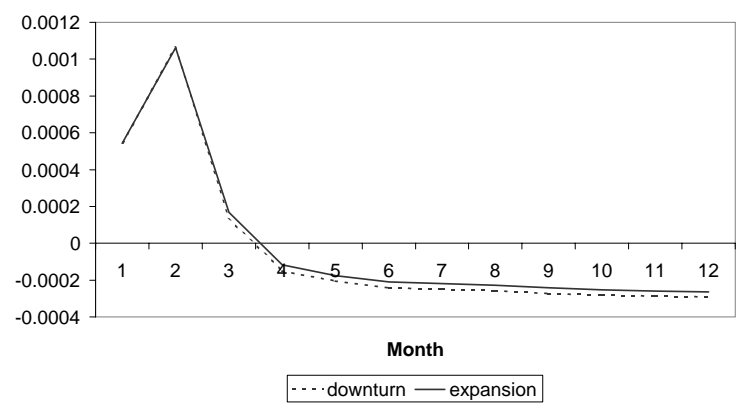

Manufacture of Rubber and Plastic Products

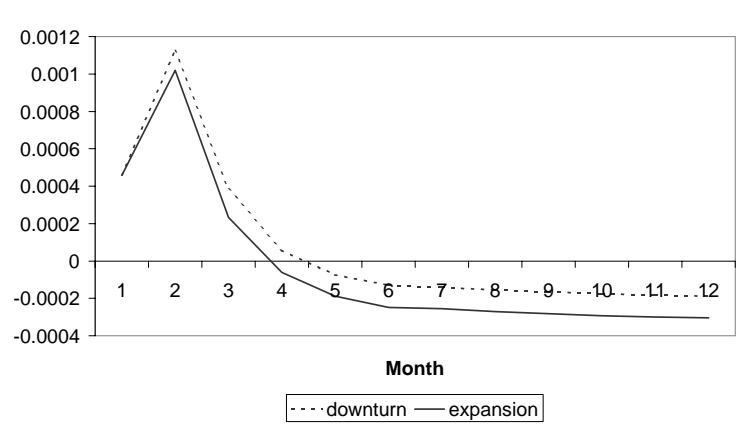

(1) The figures show the effect of positive interest rate shocks on sectoral output for different months after the shock occurs. The size of the shock is 25 basis points. 
Figure 2b. Sectoral Reactions to Positive Interest Rate Shocks (1)

Manufacture of Basic Metals and Fabricated Metal Products

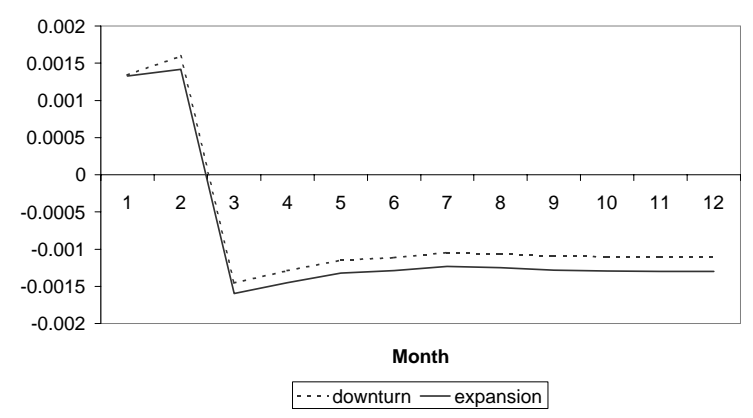

Manufacture Not Elsewhere Classified

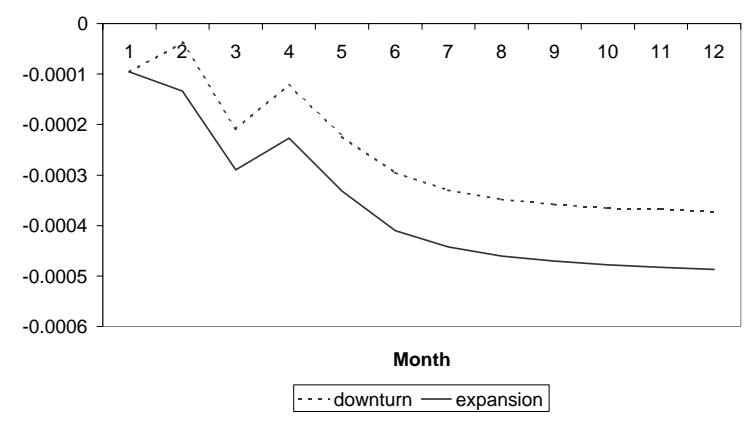

Manufacture of Machinery and Equipment Not Elsewhere Classified

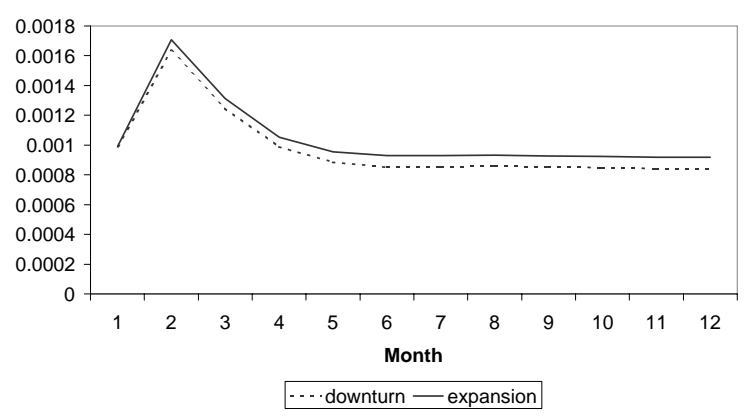

(1) The figures show the effect of positive interest rate shocks on sectoral output for different months after the shock occurs. The size of the shock is 25 basis points. 